\title{
CMR real-time, free-breathing, phase contrast flow quantification: a novel approach to assess ventricular coupling in constrictive pericarditis
}

Paaladinesh Thavendiranathan*, David Verhaert, Michael Walls, Sanjay Rajagopalan, Chung Yiu-Cho, Orlando Simonetti, Subha V Raman

From 2011 SCMR/Euro CMR Joint Scientific Sessions

Nice, France. 3-6 February 2011

\section{Background/objective}

Constrictive pericarditis (CP) is an important cause of heart failure; however, with accurate diagnosis and directed treatment it is potentially curable. Cardiac magnetic resonance imaging $(\mathrm{CMR})$ has played a diagnostic role, primarily by allowing assessment of pericardial morphology but with limited depiction of physiological changes. We sought to examine the feasibility of a novel CMR approach that enables real-time phase contrast (RT-PC) assessment of discordant respirophasic changes in trans-mitral and tricuspid flow velocity - the signature findings in $\mathrm{CP}$ - due to enhanced ventricular interdependence.

\section{Method}

Patients referred to the CMR lab pre-pericardectomy or for assessment of suspected $\mathrm{CP}$ were included. Following routine $\mathrm{CMR}$ examination for $\mathrm{CP}$, transmitral (MV) and tricuspid valve (TV) flow velocities were simultaneously obtained by through-plane RT-PC imaging during unrestricted respiration using a slice position to include both valves (Figure 1) with the following parameters: $\mathrm{TR} / \mathrm{TE}=13.7 \mathrm{~ms} / 2.5 \mathrm{~ms}$, water excitation pulse with flip angle $=25^{\circ}, 10 \mathrm{~mm}$ slice thickness, $160 \times 120$ matrix, EPI factor $=15$, TSENSE rate $=2$, slice thickness $=10 \mathrm{~mm}$, and $V E N C=150 \mathrm{~cm} / \mathrm{s}$. Shared velocity encoding was used to achieve an effective temporal

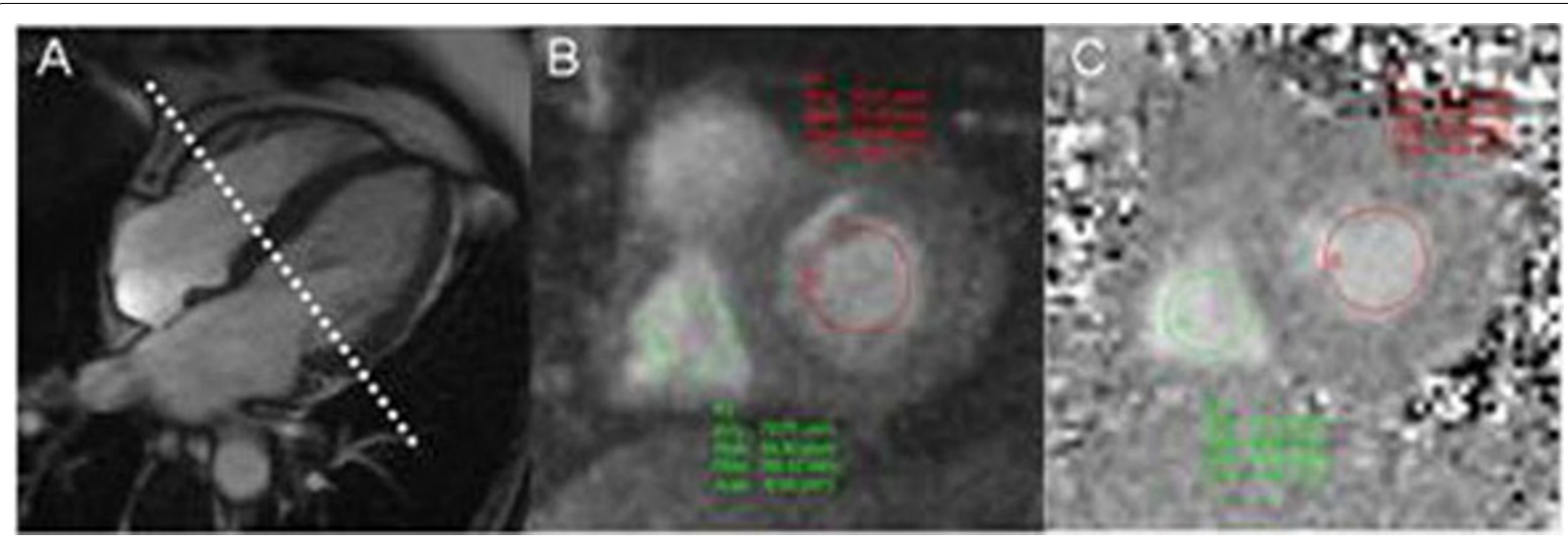

Figure 1 (A) Horizontal long axis cine image used for selection of RT-PC imaging plane. (B) Magnitude and (C) phase images obtained with RT-PC acquisition. Regions of interest for mitral inflow (red) and tricuspid inflow (green) are illustrated in both the magnitude and phase images.

The Ohio State University, Columbus, OH, USA

(c) 2011 Thavendiranathan et al; licensee BioMed Central Ltd. This is an open access article distributed under the terms of the Creative 
resolution of 55ms and typically, 200-400 phases were obtained. The diagnosis of CP was confirmed using a combination of clinical history, diagnostic imaging, invasive hemodynamic measurements, intra-operative findings, and histopathology. Regions of interest at the mid-portion of the MV and TV were chosen on the PC images (Figure 1). Peak velocity data from average of 4 neighboring pixels for both valves were displayed simultaneously (Figure 2). The percentage change in velocity were calculated for MV as (MV expiratory E velocity - inspiratory E velocity)/(inspiratory E velocity) and for TV as (TV inspiratory $\mathrm{E}$ velocity - expiratory $\mathrm{E}$ velocity)/ (expiratory E velocity).

\section{Results}

9 patients ( 7 men, age $56 \pm 17$ years) and 9 healthy volunteers (6 men, age $31 \pm 10)$ were included. All patients had increased pericardial thickness (6.3 $\pm 1.5 \mathrm{~mm}$ ), a respirophasic shift of the interventricular septum, and inferior vena cava enlargement. Discordant

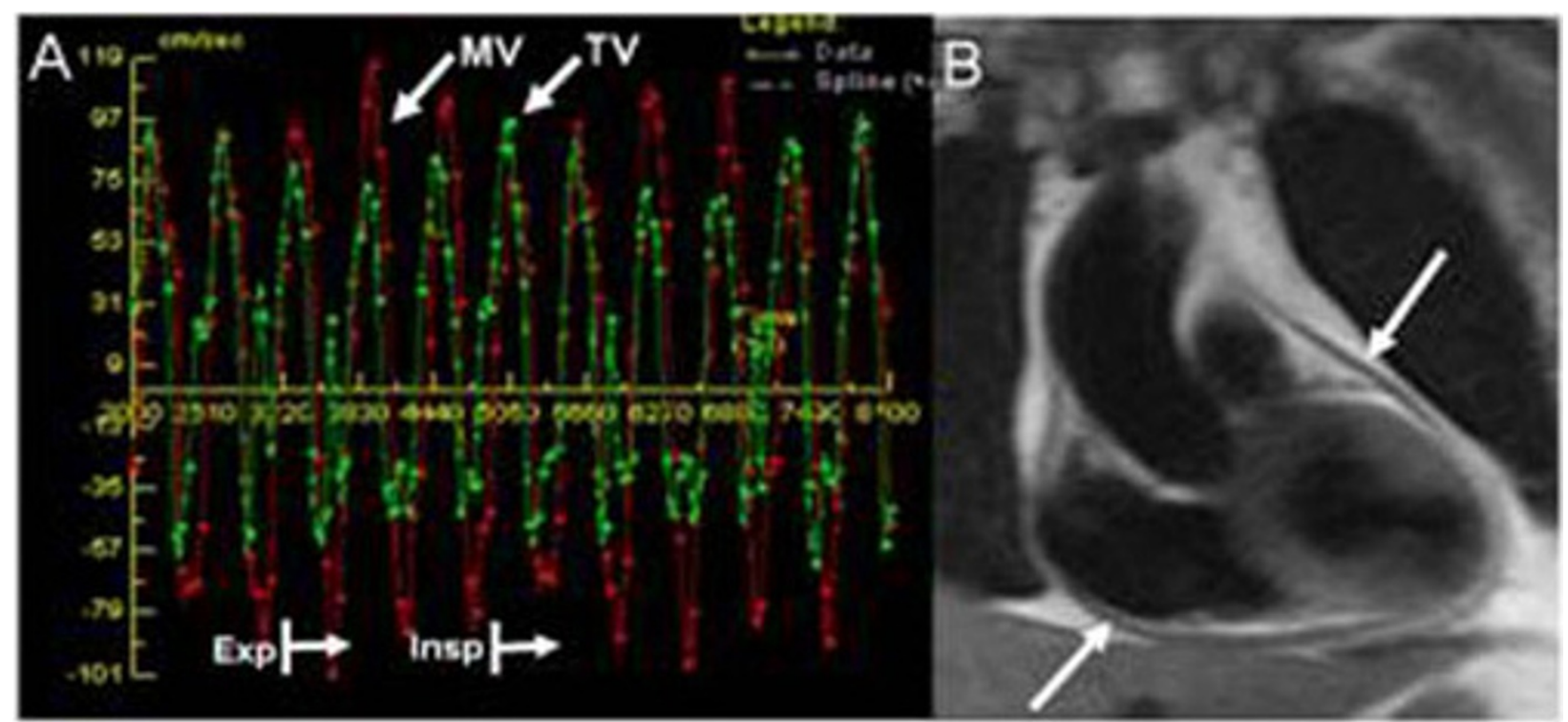

Figure 2 (A) RT-PC trans-mitral and tricuspid flow illustrating significant resiprophasic variation. (B) Dark blood turbo spin echo image illustrating pericardial thickening (arrows).

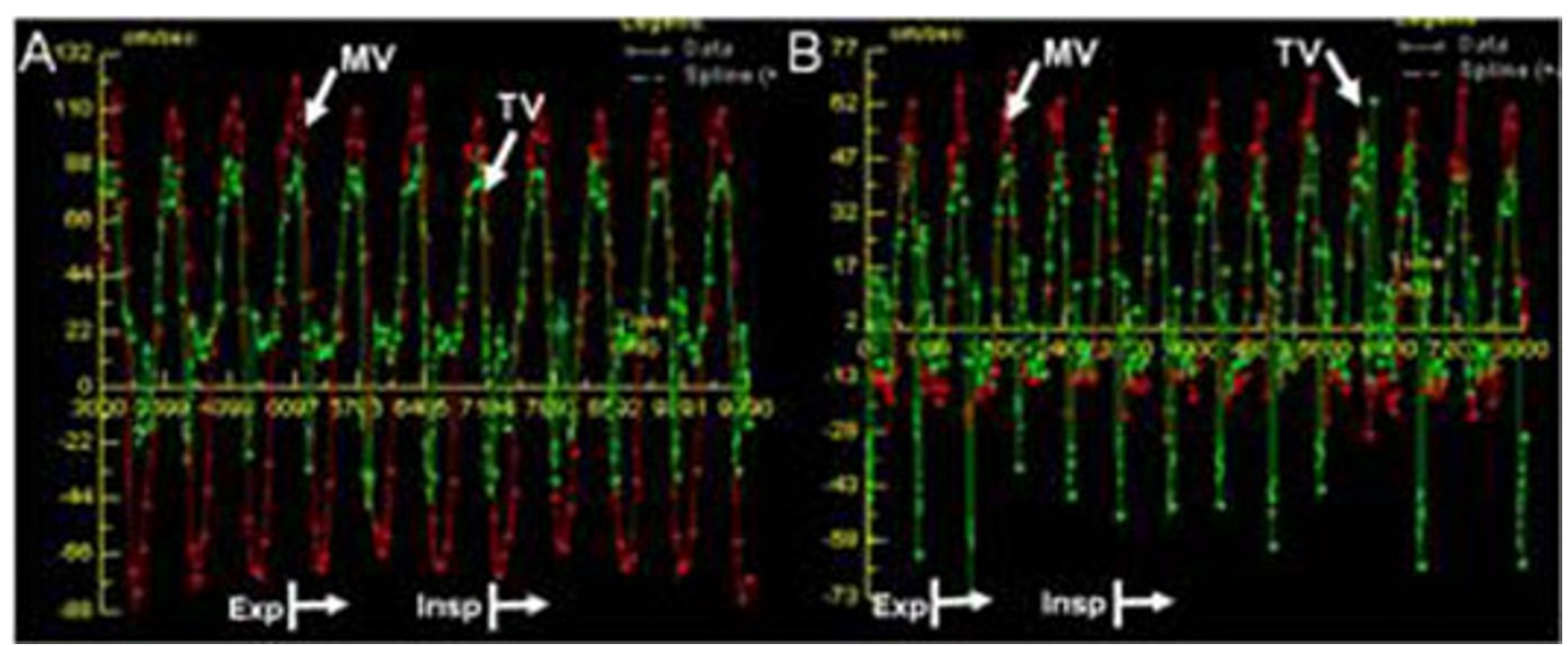

Figure 3 (A)RT-PC flow post pericardectomy in the same patient as Figure 2 illustrating absence of significant respirophasic variation. (B) RR-PC trans-mitral and tricuspid flow in a healthy volunteer illustrating lack of significant respirophasic variation. 
respirophasic flow velocities across the mitral and tricuspid valves were recorded in all CP patients (Figure 2), with mean trans-mitral and tricuspid flow velocity variation measuring $46 \pm 21 \%$ and $60 \pm 16 \%$ respectively, compared to $17 \pm 5 \%(\mathrm{p}=0.003)$ and $30 \pm 13 \%$ in controls $(\mathrm{p}<0.001)$ (Figure 3).

\section{Conclusions}

Reciprocal respirophasic changes in mitral and tricuspid inflow velocity in CP can be simultaneously displayed by RT-PC imaging. This provides essential hemodynamic information, which in conjunction with other morphological and functional changes is a useful addition to the diagnostic armamentarium of CMR for the diagnosis of CP.

Published: 2 February 2011

doi:10.1186/1532-429X-13-S1-033

Cite this article as: Thavendiranathan et al: CMR real-time, free-

breathing, phase contrast flow quantification: a novel approach to

assess ventricular coupling in constrictive pericarditis. Journal of

Cardiovascular Magnetic Resonance 2011 13(Suppl 1):O33.

Submit your next manuscript to BioMed Central and take full advantage of:

- Convenient online submission

- Thorough peer review

- No space constraints or color figure charges

- Immediate publication on acceptance

- Inclusion in PubMed, CAS, Scopus and Google Scholar

- Research which is freely available for redistribution

Submit your manuscript at www.biomedcentral.com/submit 